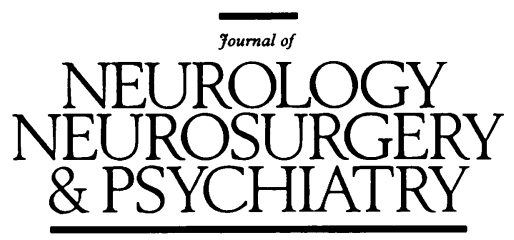

Editorial

\title{
Threats to academic neurosurgery in the United Kingdom:
}

\section{a personal view}

There have been unprecedented changes recently in the Health Service, the universities, the Royal Colleges, the General Medical Council and research funding agencies, each trying to come to terms with present and future advances in treatment, finite budgets, the aspirations of patients, the medicolegal industry, European Community law, and the conditions of training for junior doctors. How have such changes, each with its own agenda and good intentions, helped or hindered our abilities to treat our patients, to develop new and more successful therapy for the future and to train the next generation of skilful and inquisitive neurosurgeons? Such are the legitimate goals of academic neurosurgery, which is not restricted to university-based neurosurgery.

\section{Historical background}

Neurosurgery has a rich and enviable heritage of meticulous clinical observation of the clinical experiments created by disease in the best traditions of John Hunter, dating back to the end of the last century in Glasgow (Sir William McEwan), Philadelphia (W W Keen), Berlin (Fedor Krause) and London (Sir Victor Horsley). Much of the subsequent progress made in neurosurgery and its basic science has come from busy practising surgeons following the lead of Cushing and Dandy in North America and including, in the British Isles, Jefferson (Manchester), Cairns (Oxford), Dott (Edinburgh) and McConnell (Dublin). There has been no sharp division between the twin cultures of academic and clinical service within neurosurgery and little of the antiscientific culture. Many of our forefathers combined unpaid service in the State hospitals with private practice, basic research, and a variety of administrative burdens. That generation fought successfully for recognition of our specialty despite being caricatured as super-specialists and proceduralists. They extracted beds and facilities, both clinical and academic, from the empires of the selfanointed 'generalists'. They established a tradition of excellence in training of both medical and nursing staff. During the World Wars and afterwards, that generation developed a wider role for neurosurgery in society, and health care in general, in terms of health promotion, rehabilitation, medical ethics, and health economics. ${ }^{1}$ Formidable progress has been made with the management of conditions once considered to be untreatable.

\section{Staffing, plant and output}

Neurosurgery in the $\mathrm{UK}$ is based in some 36 regional and subregional centres located within teaching and large district general hospitals where NHS and University divisions of clinical neurosciences facilitate collaboration with neurologists, neuroradiologists, neuropathologists, neuroanaesthetists and neurophysiologists. This pattern is envied abroad and provides care for populations sufficiently large to permit subspecialisation and cost effective concentration of equipment, nursing expertise and training facilities. Long may it continue. The resources recommended for the conduct of 'safe neurosurgery' have been published recently by the Society of British Neurosurgical Surgeons.

Amongst some seven hundred clinical Chairs in the UK, there are six established Chairs of Neurosurgery, three recently created personal Chairs, and six Readerships or Senior Lecturerships located within Departments of Surgery or Clinical Neurosciences. Fortunately there has been enough flexibility within contracts for many of the 120 NHS consultants in neurosurgery in the UK, with the desire and initiative, to pursue clinical research. Equally, university neurosurgeons play a very full part in the clinical service, sharing the emergency workload and developing subspecialty clinical interests. The total research income into British neurosurgery, both university and NHS, is only some $£ 2$ million per annum, and yet the UK has an outstanding record of high quality publications. In the decade 1980-90, the UK published 3702 neurosurgical papers in the world literature (1884 in European and 1818 in North American journals). ${ }^{2}$ The UK publishes almost twice as many papers as any other European country despite a smaller number of consultant neurosurgeons per million of population. Unlike clinical medicine and the basic sciences, where publications from the UK are declining in number and impact, ${ }^{3}$ surgery remains steady but there is no room for complacency: yesterday's basic science is today's applied clinical neuroscience that becomes tomorrow's standard treatment.

\section{Territory and the changing face of science}

Why does academic neurosurgery matter in the context of the proposals contained in the Government document Health of the Nation? Neurosurgeons are concerned with 'surgical conditions' of the brain and spinal cord. They are not restricted to the esoteric but care for most of those acutely ill patients with neurological conditionsfor example, head injuries, haemorrhage, spinal cord compression, etc, diseases responsible for much long 
term disability in the community. Neurosurgeons also help to create standards and guidelines for the care of less seriously ill patients managed in other hospitals. Their role overlaps variably with that of colleagues in neurology, orthopaedics, faciomaxillary, plastic, ENT and ophthalmic surgery, interventional radiology and neurointensive care. Neurosurgery should guard its territory while exploring problems that may become part of the conventional neurosurgical workload of tomorrow.

What should be the scale of resource devoted to neurosurgery in the UK, within and between institutions, to facilitate research of international quality? No one individual is able to explore a whole problem. In the identity that we may call neurosurgical science, multidisciplinary collaboration is essential. Neurosurgeons should not be prescriptive about who thinks about their patients' problems, provided the patient is not put at risk. The study of the cerebral circulation is one of the major success stories of the clinical neurosciences, and reflects contributions from both clinical and basic scientists coming together in laboratories that often were not part of the conventional university science department. A major factor was that non-clinical scientists devoted themselves to a topic that initially was not part of the fashionable mainstream. One major threat to such successful ventures is the uncertain career structure for such scientists, unlike clinicians who have a well-honed training programme. Scientists based entirely in a clinical department can lose contact with their peers and the rapidly evolving concepts and technology of science. Different models of interaction may succeed or fail in different places but collaboration is easier if there is a geographically convenient research institute. Clinicians are shorn of their white coats and bleepers; basic scientists have the time to explain the principles behind their terminology and, in exchange, learn not to adorn their grant applications with inaccurate clinical jargon. Such 'integrated centralisation' facilities long term and mutually productive collaboration between clinicians, physiologists, pharmacologists, physicists, engineers, and molecular biologists. ${ }^{4}$ For similar reasons, experimental facilities cannot stand alone and, in addition, require protection from animal rights activists.

Physicists and astronomers have long since learnt that their science is regarded as expensive and that they must work together across institutional and national boundaries. Some refer to their isolationist period as their 'Stone Age'. In clinical neuroscience close collaboration with the NHS over expensive technology is essential. Stereotactic radiosurgery has been one of the success stories in terms of clinical organisation in the UK, starting in one centre with national referral of patients. Neuroimaging with new, very expensive, scanning facilities holds major promise for increasing our knowledge. Sadly, their provision in the UK has been patchy and their academic output limited. Magnetic resonance and CT imaging have provided such immediately obvious clinical benefit that there has been overwhelming pressure to 'get on with the work'. Despite liaison between the Medical Research Council and the Department of Health, only a few studies have considered if such work might have been more efficiently focused. Many of the scanners were subject to financial constraints and the net result has been a limited academic field in the home country of much of the technological innovation. Research-dedicated machines are essential to provide flexibility of timing and programming.

There is a long established tradition in the UK of multicentre trials in neurosurgery and cross boundary referral of patients.
The mushrooming of multicentre clinical trials, now overviews, may reduce the perceived contribution of the individual clinician so much that being involved as a minute $c o g$ in a large evaluation machine becomes profoundly unattractive. The problem may be alleviated by making such trials less arduous, more fun to take part in, and by giving them an educational component (Warlow, 1992). ${ }^{5}$

There is already the goodwill for the formation of research institutions and optimal use of research dedicated machinery. A healthy loyalty to one's own institution will need to be supplemented by the desire to contribute to and take advantage of national resources. Inevitably there will be greater mobility of staff than has occurred traditionally in neurosurgery in the UK, a process that may well be encouraged by the Health Service reforms and the foreshortened training period. There is no place for the destructive forces of tribalism.

\section{Training and continuing education}

Should all neurosurgeons in training undertake a fulltime period in research? How can a prospective academic neurosurgeon be guided through the present obstacle course so that he or she acquires both clinical credibility and research training, while retaining the necessary inquisitiveness and drive to continue for another thirty years? The situation has improved considerably since the time when no consultant neurosurgeon could expect to be appointed under the age of 40 years, ${ }^{6}$ with an overlong apprenticeship in general surgery and, in some cases, general medicine. The reward for some, towards the end of the apprenticeship years, was a 'thinking' year. It is remarkable that the generation who survived this initiation went on to achieve so much, ably supported or tolerated by the resilient characters of their spouses and children. So much could have changed so much more quickly had the early, foolhardy protagonists of appraisal and accreditation of training programmes been heeded.

There is a refreshing 'mistral' blowing through the General Medical Council and the Royal Colleges encouraged by the medical school deans. It is to be hoped that medical students in the future will emerge less mentally numb and more orientated towards problem solving. Potential neurosurgical trainees need to be identified at a very early stage so that they can be introduced to the basic neurosciences and to research concepts, preferably combining the $\mathrm{MB}$ with honours $\mathrm{BSc}$ or a $\mathrm{PhD}$. So many areas of medicine now require an understanding of the basic neurosciences, that it really should be possible for those subjects to be covered as a University course module to be taken at any time from the age of 18 onwards, available even through the Open University. Comprehensive basic neuroscience courses cannot be provided by any one of the UK neurosurgical units. The intention should be to expose trainees as early as possible to the spirit and philosophy of the basic neurosciences, not to demand regurgitation of dessicated facts from textbooks. The $\mathrm{MB} / \mathrm{PhD}$ programme needs to be carefully integrated with the rigours of surgical training if physicians are not to take all of the slots.

The American view ${ }^{7}$ mirrors the British one that research training for most trainees who will follow a clinical career should have two main goals. The first is to become aware of what science offers and to develop skills necessary to evaluate the evidence for new concepts and effectiveness of therapy. The second is to acquire techniques for systematic observation. These skills will improve the trainee's clinical abilities and provide the basis for initial evaluation of reports in the literature. A 
period of full time research within the training period is highly desirable ${ }^{8}$ for all trainees, but when, and for how long? The present pattern of training in the UK is in imminent process of change ${ }^{9}$ from pre-registration (one year), basic surgery (three to four years), old FRCS, career registrar (two years), research (one to two years), senior registrar (two to four years), intercollegiate exam and accreditation to preregistration (one to two years), basic training (two years), college diploma, five years in a single run-through training grade and the intercollegiate diploma, culminating in the addition of the initials "CT" in the register. A subspecialty training year may follow. One year of higher surgical training should be allocated to research including audit and be paid for by the NHS via the postgraduate deans. This research period needs to combine structured teaching with competently supervised research, including audit. A further one to two years will have to be taken out of the higher surgical training period or before, if a higher degree is to be obtained. Three continuous years ${ }^{10}$ away from surgery is neither realistic nor fair to the trainee who would face a very stressful period on his or her return. Flexibility should not be difficult now that 'accreditation is dead'. A competitive edge needs to be retained and each stage of the training programme critically appraised with early identification of those trainees who would be best advised not to pursue a neurosurgical career.

This welcome change in training and working hours will result in a reduction in junior staffing to undertake research. The training numbers within neurosurgery have been carefully disciplined so that these changes, despite only a modest effect on the number of research fellows, will shrink the academic training pool.

Consultants will be replaced by specialists who will have been ejected from their training programme at about the age of 31 or 32 years to be promoted $10-15$ years later to Senior Specialist. Inevitably the bulk of emergency work will fall on the shoulders of the 31-45 year old whose role in reality will be akin to that of a present day Senior Registrar, albeit with progressively more independence and the dubious benefit of 'further career goals, opportunities and mobility'. This is the age at which much creative work is done and it is essential to provide the time and facilities for research. Specialists should beware of the potential tyranny of overspecialization in a more commercially minded NHS.

The intercollegiate exam in surgical neurology is taken after at least one year as a senior registrar and contains both multiple choice and viva examinations in the basic neurosciences as well as a clinical examination. We are all much in debt to those who have engineered the changes in the FRCS but my personal belief is that this assessment is proving to be more of a capricious obstacle to the able individual's self improvement than was envisaged originally. Evidence for this statement comes from talking to, and interviewing trainees, and from the decline in entries for prestigious research essay competitions. Graduates from countries outside the European Community would be attracted by a combined training and research post but that valuable reservoir of talent is wary of the present, rather prescriptive, admission criteria for the intercollegiate examination.

There is a need for more flexibility and that is also the view of our North American colleagues with respect to their Board examination. ${ }^{7}$ Basic neurosciences should be studied much earlier and the multiple choice questions examination taken whenever the candidate feels competent. The reading required would help some to identify areas of research of interest to them. The clinical component should be simply a bedside examination of the candidate's ability to assess a patient and provide a coherent plan of management.

To complicate matters there is now a voluntary diploma (two stage examination) awarded by the European Board of Neurosurgery. In part this has grown out of the excellent five year cycle of training courses organized by the European Association of Neurosurgical Societies and a desire to provide a qualification analogous to the American Board Examination in Neurosurgery. The European Board does not intend to interfere with or limit the professional activities of any duly licensed physician whom it has not certified. The Board is closely linked with the Neurosurgical Committee of the Union Européenne de Médecins Spécialistes (UFMS) which aims to harmonise European requirements as they concern the neurosurgical specialist.

Is neurosurgery becoming too bureaucratic? $\mathrm{Sir}$ William Osler expressed similar concerns in 1905: 'Perfect happiness for student and teacher will come with the abolition of examinations, which are stumbling blocks and rocks of offence in the pathway of the true student'. ${ }^{11}$ Dutch neurosurgery has no exam. Perhaps examiners should have training of similar rigour to that provided by the Royal College of General Practitioners and reasons given for failure of unsuccessful candidates. ${ }^{12}$

Research funding, collaboration with industry and trust hospitals, therapeutic orphans and the focus of budgets.

The decline in British basic science has been well documented $^{13-15}$ and linked to a decline in the national economy finessed by unsympathetic caricatures of academic life. Occasional apologists argue by analogy with other countries that this decline in government funding may actually stimulate research. It is argued that there should be greater reliance on contracts from industry and government departments. This fails to recognise where genuine advances come from. It is regrettable that the ministries and the city failed to capitalise on British inventions that generated enormous amounts of money, such as medical imaging and monoclonal antibodies, among others. Fortunately the Medical Research Council is fighting back and the splendid system of medical charities in the UK has partly protected the neurosciences. Grant support for clinical research in patients, however, may have declined, ${ }^{16}$ many charities are oriented towards particular diseases or institutions, and there is no major charity targeted at neurosurgical conditions. On the initiative of Mr Peter Hamlyn and the Society of British Neurological Surgeons, the British Brain and Spine Foundation has been formed to fill that gap and support research into neurological conditions that are not adequately provided for elsewhere, particularly through funding Clinical Research Fellows.

Industrial funding has become very important to British neurosurgery with some very successful and imaginative collaborations. There are dangers, however, in over-reliance on industrial funding that include dominance by patentable drugs and susceptibility to the vagaries of industry, the stock market, an overconservative insurance industry, and intercontinental selling of knowledge databases. Some neurosurgical patients may not be sufficiently numerous to prove attractive to the marketing divisions of pharmaceutical companies. Much neurosurgical research is not drug orientated. There may be insufficient profit in drug trials to provide secure funding for unrelated research. Pharmaceutical companies are often multinational and may insist on international cooperative studies under foreign direction. Such academic 
colonialisation may so shackle the limited pool of the neurosurgical clinical research population that a separate British trial may be seriously undermined in that particular condition for a period of years. One company may be able to 'shut out' another company and distort academic progress. It is going to be very difficult to create the drug cocktail that may be necessary to treat cerebral ischaemia and acute brain injury. Step by step trials involving at least two or three different companies may be requiredrumour has it that such collaboration has proven difficult. Finally, for understandable medicolegal reasons, some regulatory authorities are acquiring the reputation for being unduly negative and threatening to induce a 'death spiral of innovation', particularly in small markets such as neurosurgical equipment.

Where will the NHS reforms, the purchaser/provider concept and trust hospitals lead us?

The central policy issue is not competition or regulation but the identification of the cost effectiveness of competing therapeutic interventions. Instead of wasting scarce resources on the redisorganization of health care structures and the often ill-conceived expansion of management, greater efforts to identify good practice and create islands of rationality in the oceans of medical uncertainty would unite both clinical and non-clinical managers. Without this unity, together with increased evaluative research, planned markets will exhibit the unwelcome characteristics of the past: ill-informed choices fuelled by the rhetoric of self-interest (Maynard, 1992). ${ }^{17}$

Unregulated market mechanisms and 'macho'18 management may prove very destructive of the goodwill that has supported the NHS since its inception. The tide has turned firmly in favour of critical evaluation of any investigation or treatment including the use of randomised trials and cost benefit analysis, promoted by health care professionals, health economists and patient-support groups alike. The public will be able to judge what needs are not being met and whether it is satisfied with the level and deployment of funding. ${ }^{19}$ Uniquely, neurosurgery has bared its soul and analysed the costs and benefits of the broad range of conditions that it treats. ${ }^{20}$ It is not the expensive surgical Cinderella of popular mythology but treats most of its patients inexpensively and effectively compared with other areas of medicine. Neurosurgery has a history of frugal living: $\mathrm{Mr}$ O'Connell at $\mathrm{St}$ Bartholomew's Hospital was warned in 1939 that he was using too much Elastoplast for supporting the heads of his patients, and that this was over-running the tight funds available to a hospital dependent on endowments. ${ }^{21}$

Trust hospitals present a considerable opportunity for change but inevitably there is friction between the short term tactics of the market place and the long term strategies of both academic medicine and far-sighted hospital directors. The NHS has been an invaluable facilitator of clinical research and evaluation: the private sector undertakes little significant research or development. Freedom of speech is essential to academic medicine but may conflict with commercial advocacy: the recent guidelines have received a mixed reception. ${ }^{22}$ Minutes must be kept of audit meetings if care is to improve. The fruits of research must be made freely available and not kept secret to attract contracts.

Neurosurgery should remain based in coherent regional units in which all the skills of neurologists, neuropathologists, neuroradiologists, neuroanaesthetists and neurosurgical nurses are brought to bear. Such regional units have a sensitive relationship with district general hospitals where most patients are assessed first. Attempts to create second rate neurosurgical units in district hospitals based on 'stripping off' low cost but profitable conditions would prove enormously destructive both to neurosurgical training programmes and to academic endeavour that requires to be based on credible patient populations. Herein lies one danger of shortening the specialist training period and 'flooding the market' with inexperienced, but paper-qualified, specialists from countries who exert no control over medical staffing numbers and whose training systems are inferior to our own. Our patients, our academic resources and the rights of our young people to enter neurosurgery on the basis of merit are all under threat. There is also the possibility of the NHS having to face yet more claims for medical negligence arising from inappropriate care..$^{23}$

When establishing contracts for services, health authorities should look closely at the cost and benefits of what they buy and hospitals should consider in detail the relative costs, benefits, and effectiveness of what they provide. Any contract negotiations must take into account the overall case mix and the demands of training. Neurosurgeons must be present at such negotiations. Cross boundary referrals must continue unfettered by excessive budgetary paperwork. One danger is that, without discussion, the very patients in whom treatment is not very effective and who should be included in clinical trials, such as those with severe diffuse brain injury and malignant brain tumours, may be at risk of being retained in the district hospital to reduce costs. The selection of patients whose management is cost effective must be accompanied by a clear intent to improve management that is currently ineffective. The laudable drive to cut waiting lists and shorten hospital stays must be matched by a clear mechanism to fund 'research' populations of patients so that they can be managed within the neurosurgical unit for as long as required.

The creation of the research and development initiative at the Department of Health under Professor Peckham with the network of regional directors is vital to the future health of academic neurosurgery. Designated funds for teaching and research (SIFTR) without detailed breakdown of the 'knock-for-knock' relationship (France Committee) must be protected. ${ }^{24-26}$ The costs of clinical research over and above normal practice should be made available with the minimum of bureaucracy. Hopefully the Peckham machine will ensure that all Health Service initiatives, both managerial and clinical, are subject to the discipline of clinical trials and money spent only by those competent to undertake research and development. A few percent of the many tens of millions of pounds squandered by one regional health authority on information technology that never functioned, would have paid for the magnetic resonance scanner-that expensive toy for doctors denied to the clinical neurosciences for a decade. ${ }^{27}$ Patients were exposed unnecessarily to outmoded investigation and unrepeatable academic opportunities lost. A total of $£ 2.5$ million was wasted in another region on a consultancy contract designed to find efficiency savings. ${ }^{28}$

One problem that the Health Service reforms has highlighted is the scope and focus of a particular budget. It is very difficult to define how much is spent on patients with severe head injuries in a region and whether more investment earlier might reduce the subsequent cost to the community by reducing the number of the severely disabled. Every new drug of proven efficacy in the clinical neurosciences, including levodopa and nimodipine, has met with the refrain that it cannot be afforded. It should be obvious that the additional expense of a new drug or procedure should be considered in the context of overall cost effectiveness of patient management and return to the community, rather than simply in terms of the immediate burden on the neurosurgical budget. For example, 
each bad outcome averted by nimodipine after subarachnoid haemorrhage costs about $£ 3900$ but each severe disability not averted costs at least $£ 500000$ in long term care. $^{20}$ But this cost may fall upon someone else. Unfortunately the person who controls local budgets holds the power. It makes no sense to have a budgetary system that is too 'micro' and not sufficiently 'macro' to relate to the clinical overview of patients from initial presentation to final outcome. Academic vigour can be wasted in fighting such self-inflicted problems of NHS organisation.

\section{Recruitment}

Academic neurosurgery in general is expanding slowly in the UK, so why should we be concerned? Firstly, trust hospitals may not continue to be so flexible with NHS consultants/specialists' time and there is, albeit anecdotal, evidence that it is proving more difficult for them to sit on national committees or examine, for example. The time for research and personal audit needs to be carefully protected and that might best be achieved by including some formal sessions within the consultant plans. Secondly, there are problems with recruitment into career university posts in neurosurgery for many reasons common to all university medicine ${ }^{29}{ }^{30}$ : lack of pay parity and conditions of service, perceived capriciousness of research funding, inadequate recognition of workload, uncertain promotion prospects, loss of tenure, and uncertainty over long term funding. The annual debacle over funding the full pay award for clinical academics is silly, but serves cynically to distract attention from other problems facing clinical academic staff. At a junior level additional duty hours may be paid at a lower rate for academics compared with NHS doctors. ${ }^{31}$ Senior registrars with substantial overtime payments may take significant drops in salary if they were to become a senior lecturer with honorary consultant status. Promotion prospects for specialist surgeons are uncertain - they have always been poorly represented in universities but the blame for that situation may lie in many quarters.

The issue of private practice for personal rather than institutional gain is particularly irksome. Academic surgeons pride themselves in the main on providing as skilled a clinical service as their NHS colleagues and yet many universities continue to forbid their using their skills in the private sector for personal gain, even though consultancies for personal gain are allowed elsewhere in the same university. The robust individualism of surgery sits uneasily with too many restrictions: a university should be a church broad enough to embrace a wide spectrum of contributors. Aird ${ }^{6}$ expressed it succinctly:

Usually a University Consultant is allowed to engage to a limited extent in private practice, his fees being paid to a research fund in his department or in his medical school. This prevents the exclusion and insulation of the university clinician from the satisfaction and from the discipline of private practice, while protecting him from the temptation of avarice.

Discussion over this issue has been heated, particularly where a straight fight has developed within a faculty between surgeons and other proceduralists on the one side, and the much greater number of representatives from the less sleep-depriving disciplines on the other, inflamed sometimes by the intrusion of personal politics. Surgeons have shown commendable restraint but the issues are complex. Private practice puts precious research time at risk if neither syndication nor facilities are available within the teaching hospital. In Canada, the universities are reported to have become dependent on the earnings of full time faculty, particularly the profitable proceduralists, to support operating costs. ${ }^{32}$ The principle of protecting the 'academic life' of full-time faculty has given way to exploitation of faculty by a financially oppressed university. The University Funding Council's research selectivity exercise puts great emphasis on individual productivity: there can be no weak links and there are no spaces on the form for excellence in clinical practice, NHS or private, however essential such excellence is for providing the base for clinical research.

\section{Time management}

Most clinical academic staff want more time to pursue research interests without becoming overburdened by excessive paperwork and bureaucracy or an overall workload greater than that of those working solely in the NHS. Publicity has been given recently to the problem of stress in doctors and the 'avoidable' pressures that could help relieve it. Would that we could share in the lifestyle of Sir Geoffrey Keynes of breast, thymus, and blood transfusion fame. ${ }^{33}$ Time is as great an impediment to surgical research as money. With all the changes in the Universities and Health Service and the demands of patients, each microcosm has very good reasons for the design of its checks and balances, but there is too much Brownian motion; too much serial and not enough parallel processing.

I realize that this questionnaire will add to your administrative burden, particularly as it follows so soon after the UFC Research Assessment Exercise. In mitigation, I can only stress how important it is for us, in formulating our future policy, to have the benefit of views and advice...

Grantsmanship has become a full time activity but we must not move to a time when academics are not credible surgeons. Neurosurgery must not surrender its heritage to those with less appetite for the clinical coalface. Paperwork is a suitable case for the staircase of audit. There is too much hand wringing over the time constraints of academic surgeons and not sufficient rationalisation of paper and provision of the infrastructure to process it.

\section{Summary}

Money, or lack of it, is but one, albeit very important, threat to academic neurosurgery. This review has rambled over some of the other minefields and self-inflicted hurdles. The path of academic progress is long and tortuous. Time has to be found in neurosurgery to examine critically the opportunities and threats posed by a changing world to our goals of establishing standards of patient care, research, and the flexible training of the next generation.

Academic Neurosurgery Unit,

J D PICKARD

Addenbrooke's Hospital,

Hills Road,

Cambridge CB2 2QQ, UK

I am very grateful to Professor J D Miller and Professor G M Teasdale for their constructive criticisms.

1 Jennett B. High technology medicine-benefits and burdens. (Rock Carling Fellowship Series). London: Nuffield Provincial Hospitals Trust, 1983. Fellowship Series). London: Nuffield Provincial Hospitals Trust, 1983. Trojanowski T, Rabow I, Rabow L. Neurosurgical publicat
European journals. Acta Neurochir (Wien) 1992;116:98-106.

3 Anon. Critical condition: clinical research in UK fading fast. Sci Watch 1992;8:1-2. 
4 Weatherall $\mathrm{D}$. The physician scientist: an endangered but far from extinct species. Br Med f 1991;302:1002-5.

5 Warlow CP. Hither neurology: research. $f$ Neurol Neurosurg Psychiatry 1992;55(Suppl.):26-31.

6 Aird I. The making of a surgeon. London: Butterworths, 1961.

7 Ojemann RG. Training the neurosurgeon for the twenty-first century. Surg Neurol 1992;37:167-74.

8 Taylor I. Opportunities for research in surgical training. Bull Ann R Coll Surg Engl 1993;75:31-2.

9 Department of Health. Hospital doctors: training for the future. Report of the Working Group on Specialist Medical Training. London: Department of Health, 1993.

10 Smith R. Academic medicine: plenty of room at the top. Too many barriers to getting well trained. BrMed F 1993;306:6.

11 Osler W Counsels and ideals. Boston: Houghton, Mifflin, 1905.

12 SCOPME. Formal opportunities in postgraduate education for hospital doctors in training. London: Standing Committee on Postgraduate Medical Education, 1992.

13 Cabinet Office (Office of Science and Technology). Annual review of government funded research and development 1992. London: HM Stationery Office, 1992.

14 Save British Science. Dual Support for Academic Research, Box 241, Oxford OX1 3QQ, 1992

15 Richmond M. A future for British science. Nature 1991;353:379-82

16 Ahrens EH. The crisis in clinical research. Oxford: Oxford University Press, 1992:326.

17 Maynard A. Planned markets and public competition (book review). Lancet 1992;340:538.
18 Simpson J, Smith R. 'Macho' management in the NHS - may correct everything. Br Med f 1992;304:1586.

19 Howell JBL. Re-examining the fundamental principles of the NHS. $\mathrm{Br}$ Med f 1992;304:297-9.

20 Pickard JD, Bailey S, Sanderson H, Rees M, Garfield JS. Steps towards cost-benefit analysis of regional neurosurgical care. Br Med $\mathcal{f} 1990$; 301:629-35.

21 Upton P. Fohn O'Connell-man of Barts (1989). Privately printed by the author. 3 St Cross Back Street, Winchester, SO23 9SB

22 Dean M. A gag on whistleblowing. Lancet 1992;340:1277-8.

23 Forsthe A Commistering . Lancet 1992;340:1277-8. (1993;306:872-3. regions. Br Med f 1993;306:872-3.

24 Chantler C. Service increment for teaching and research. $\mathrm{Br} \mathrm{Med} f$ 1992;305:71-2.

25 Smith C. Service increment for teaching and research (SIFTR): the Southampton experience. $\mathrm{Br} M e d \mathcal{F} 1992 ; 305: 97-8$.

26 Clack G, Bevan G, Peters JJ, Eddleston ALWF. Kings model for allocating service increment for teaching and research (SIFTR). $\mathrm{Br} \mathrm{Med} f$ 1992;305:95-6.

27 Warden J. The Wessex fiasco. Br Med F 1993;306:1292.

28 Seton $C$. Health chiefs wasted $£ 2.5 \mathrm{M}$ in savings drive. The Times September 11th, 1992

29 Peters DK. Academic medicine. Br Med f 1992;304:651-2.

30 Medical Academic Staff Committee. Annual Report. Br Med 71992

31 Bradbury MG. Raw deal for academics. Br Med 7 1992;304:1058.

32 Eastwood MR, Provan JL. Canada: The doctors dilemma. Lancet 1991, 338:242-3.

33 Keynes G. The gates of memory. Oxford: Clarendon Press, 1981.

\section{Neurological stamp}

\section{Johann Wolfgang von Goethe (1749-1832)}

The great German poet, dramatist and philosopher eventually ranked science as important as his poetic activity. He was the first to use the term morphology, and recognised in the human species the intermaxillary bone (premaxilla) (1786). Goethe considered that the skull was made up of modified vertebra and the jaws of insects as being modified limbs. He was also interested in the concept of evolution, in optics and also contributed to the physiology of colour vision. Goethe was instrumental in having Purkinje appointed Professor of Physiology and Pathology at the University of Breslau in 1823.

Goethe's understanding of the association of aphasia with stroke is clearly shown in his William Master's Apprenticeship, which he wrote in $\mathbf{1 7 9 5}$.

My father was suddenly seized with palsy, which attacked his right side and deprived him of the power of speech. We were obliged to guess at everything he wanted, for he never expressed the words which he intended to utter. Often times this was to me fearfully distressing, particularly on occasions when he insisted upon being left alone with me-he would signify, by violent gestures, that every other person should retire; but when we were left together he found himself unable to express his thoughts.

Goethe is shown here on a stamp issued by Luxembourg in 1977 (Stanley Gibbons 981, Scott 593).

L F HAAS

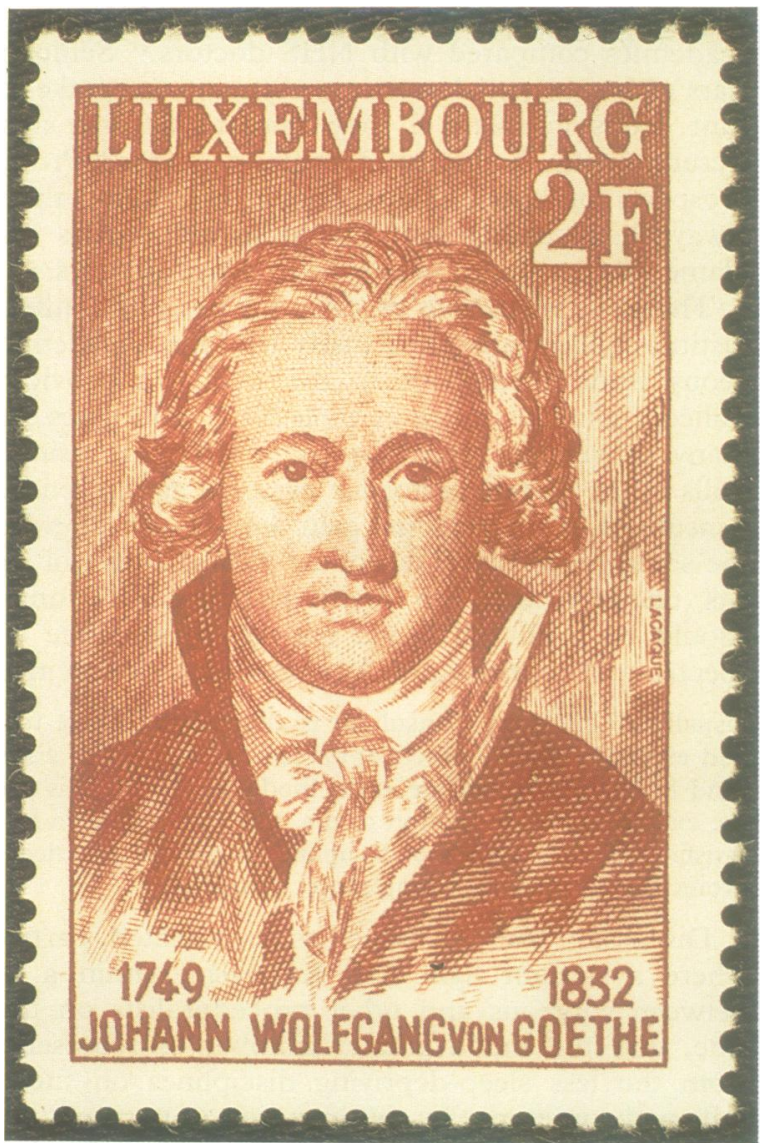

